\title{
Comparison of the histological methods in the diagnostic of deer cysticercosis
}

\author{
M. GOLDOVÁ ${ }^{1 *}, \check{S}$ TÓTH ${ }^{2}$, V. LETKOVÁ ${ }^{1}$, J. MOJŽIŠOVÁ $^{1}$, I. KOŽAROVÁ ${ }^{1}$, M. POMFY $^{2}$
}

\author{
${ }^{1}$ Department of Parasitology, University of Veterinary Medicine, Komenského 73, Košice, Slovak Republic, \\ ${ }^{2}$ Department of Histology and Embryology, Faculty of Medicine, P. J. Šafárik University, Šrobárova 2, Košice, \\ Slovak Republic
}

\begin{abstract}
Summary
Histochemical methods for the detection and diagnosis of the developmental stages of the canine tapeworm, from the genus Taenia found in the heart and lungs of red deer (Cervus elaphus) and roe deer (Capreolus capreolus) hunted in Eastern Slovakia, is presented here. Detailed morphology of cysticerci (Cysticercus spp.), based on microscopic and histochemical analysis is described. For confirmation and demonstration of PAS-positive substances in the body of parasitic tissue (tegument and mesenchyme) the McManus - PAS method was used. The histochemical method according to Van Kossa was very effective for confirmation of calcareous corpuscles, which are one of the most important histological markers of cestode tissues (larva or adult).
\end{abstract}

Key words: cysticercosis; deer; histochemistry; histology

\section{Introduction}

Cysticercosis is a worldwide parasitic infection of domestic and wild animals and humans. Cysticercus, a larval stage in the cestode life cycle which is a fluid-filled cyst containing an attached single invaginated scolex, typically found in intermediate hosts. In the present study we have attempted to give a more emphasis on cysticercosis specifically in cervids. Canidae, mainly red fox and wolf, serve as final hosts. Free-living ruminants, like cervids while grazing pick up eggs and act as intermediate hosts of various tapeworms. In cervids, especially in roe deer, cestode larvae are often detected in the musculature (myocardium, and skeletal muscle), lung, liver and brain. The larval stages are of great importance than their adult stages, due to their pathogenesis. The histopathological changes frequently noticed are: atrophy, necrosis, caseation or calcification of muscle tissue.

Cysticercus cervi, the larval stage of the carnivore ta- peworm, Taenia cervi (Christiansen, 1931) has been repeatedly considered synonymous to larval stages of Taenia krabbei Moniez, 1789 or Taenia ovis Cobbold, 1869 (Murai \& Sugár, 1979; Verster, 1969). It is not possible to differentiate between Taenia ovis and T. krabbei on morphological grounds with certainty. For differential diagnosis, several biological characteristics were used. Red deer have been reported to be refractory to Taenia ovis infection whereas other potential intermediate hosts like cattle, goats, pigs and sheep have been shown to be refractory to T. krabbei (Flueck \& Jones, 2006).

The incidence of cysticercosis in cervids was recorded in Yugoslavia (Rukavina et al., 1973), Czech Republic (Kolár et al., 1978), Russia (Romanenko, 1988) and Poland (Tropilo et al., 2001). Information of the incidence of Cysticercus spp. in deer in Slovak Republic are incomplete and sporadic (Mituch, 1969; Kotrlý \& Kotrlá, 1977).

In case of suspected pathoanatomic medical finding it is necessary to confirm degenerating cysticerci by direct histopathological examination. In our study we described the histopathological diagnosis of tissue infestation by cysticerci in red and roe deer. These methods emphasize structures typical for larval stages of cestodes, i.e. cysticercus, designated like the most important histological markers. The aim of present study is the evaluation of various basic, special and histochemical staining methods for diagnosis of deer cysticercosis.

\section{Material and methods}

\section{Animals and experimental design}

During standard field necropsies, six cysticerci were obtained from the hearts, localized on pericardium and under the epicardium of a two-year-old male red deer (Cervus elaphus) and a three-year-old female roe deer (Capreolus capreolus). From the lungs of a four-year-old male roe 
deer three cysticerci were collected, which were localized under the visceral pleura in the lung parenchyma. All collected cysticerci were viable, well-developed with transparent envelopes filed with transparent fluid and contained an invaginated scolex. All animals included in the experiment were hunted in the Eastern Slovakian region. During the autopsy, special attention was given to the anatomical changes in cardiovascular and respiratory systems.
One quarter of total number of sections was stained with special staining methods: Goldner's modification of green trichrome (GGT), Masson's blue trichrome (MBT), and Van Gieson's picrofuchsin (VGP) (Vacek, 1995). The GGT and MBT determined the distribution of muscle, collagen fibres, fibrin and erythrocytes. VGP staining method also demonstrated collagen.

The histochemical methods for evidence of calcium accor-

Table 1. Survey of various histological staining methods with microscopic results

\begin{tabular}{|c|c|c|c|c|c|c|}
\hline $\begin{array}{c}\text { Tissue } \\
\text { components }\end{array}$ & $\begin{array}{c}\text { Hematoxylin } \\
\text { \& Eosin }\end{array}$ & $\begin{array}{c}\text { Goldner's } \\
\text { Green } \\
\text { Trichrome }\end{array}$ & $\begin{array}{c}\text { Masson's Blue } \\
\text { Trichrome }\end{array}$ & $\begin{array}{l}\text { Van Gieson } \\
\text { Picrofuchsin }\end{array}$ & PAS & Van Kossa \\
\hline nucleus & violet & blue & blue/black & brown/black & - & - \\
\hline cytoplasm & pink & pink & red & yellow & - & - \\
\hline erythrocyte & red & orange & pink/red & - & 一 & - \\
\hline muscle tissue & $\mathrm{red} / \mathrm{pink}$ & purple/red & red & yellow/brown & - & - \\
\hline collagen fibres & pink & green & blue & red & 一 & - \\
\hline elastic fibres & - & - & red & yellow & - & - \\
\hline $\begin{array}{c}\text { polysaccharide } \\
\text { (e.g. glycogen) }\end{array}$ & - & - & - & - & pink/red & - \\
\hline calcium & - & - & - & - & - & brown/black \\
\hline
\end{tabular}

\section{Histological investigations}

Tissue samples with cysticerci obtained from the heart and lungs were fixed in $10 \%$ neutral buffered formalin and subjected to routine paraffin processing. $180-200$ histological sections $(5-6 \mu \mathrm{m}$ thick) per cysticercus were prepared. Some of these these sections were stained with hematoxylin-eosin (H\&E) as described Čunderlíková and Balážová (1990).
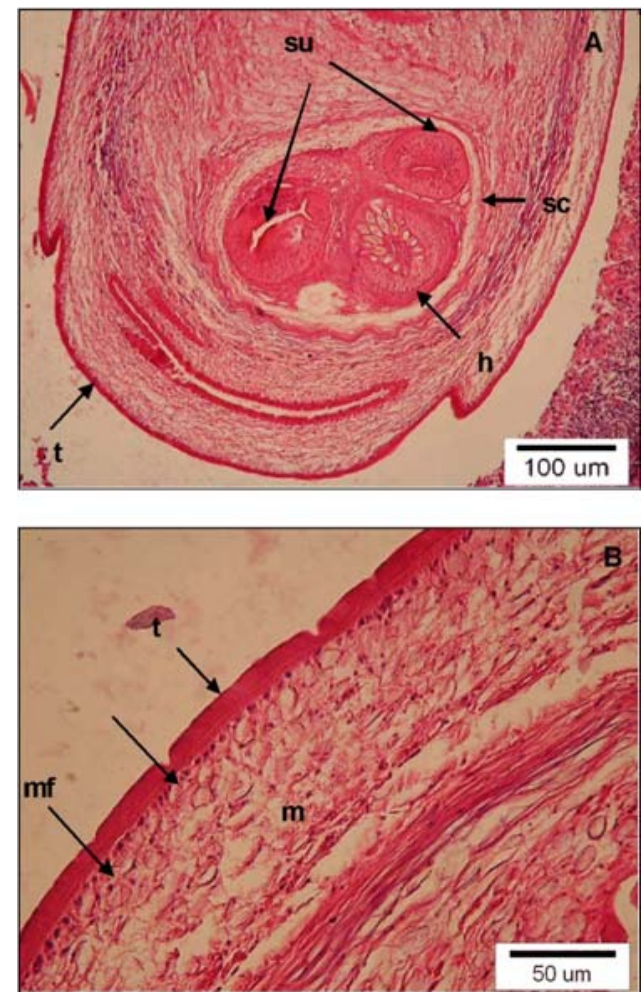

Fig.1. The neck region of cysticercus. Tegument ( $\mathrm{t}$ ), invaginated scolex (sc), suckers (su), hooklets (h), basal layer (bl), muscle fibres (mf), mesenchyme (m) (H\&E, heart, A - 200x, B - detail, 400x) ding to Van Kossa (VK) and Periodic Acid Schiff (PAS) method according to McManus for evidence of carbohydrates were used in about $10-15$ of histological sections (Čunderlíková \& Balážová 1990) (Tab.1). The classic staining method for the demonstration of calcium and certain other salts in tissues is that of VK method. The PAS staining is used to demonstrating carbohydrates (glycogen, glycoprotein, proteoglycans). It is used to distinguish diffe-
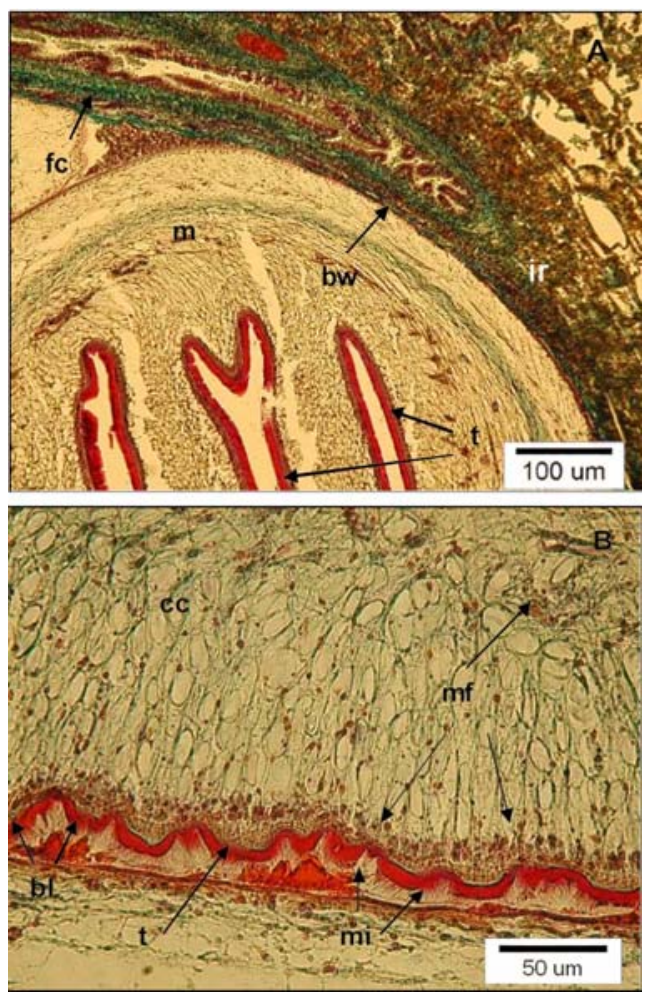

Fig.2. Goldner's green trichrome staining method. Bladder wall (bw), fibrous capsule (fc), inflammatory reaction (ir), tegument (t), mesenchyme (m), microvilli (mi), basal layer (bl), muscle fibres (mf), calcareous corpuscules (cc) (lungs, A - 100x, B - detail, 400x) 
rent types of glycogen storage pathological processes in tissues. Sections utilizing all these staining methods were dehydrated in alcohols, cleared in xylene, and mounted in Entellan (Merck).
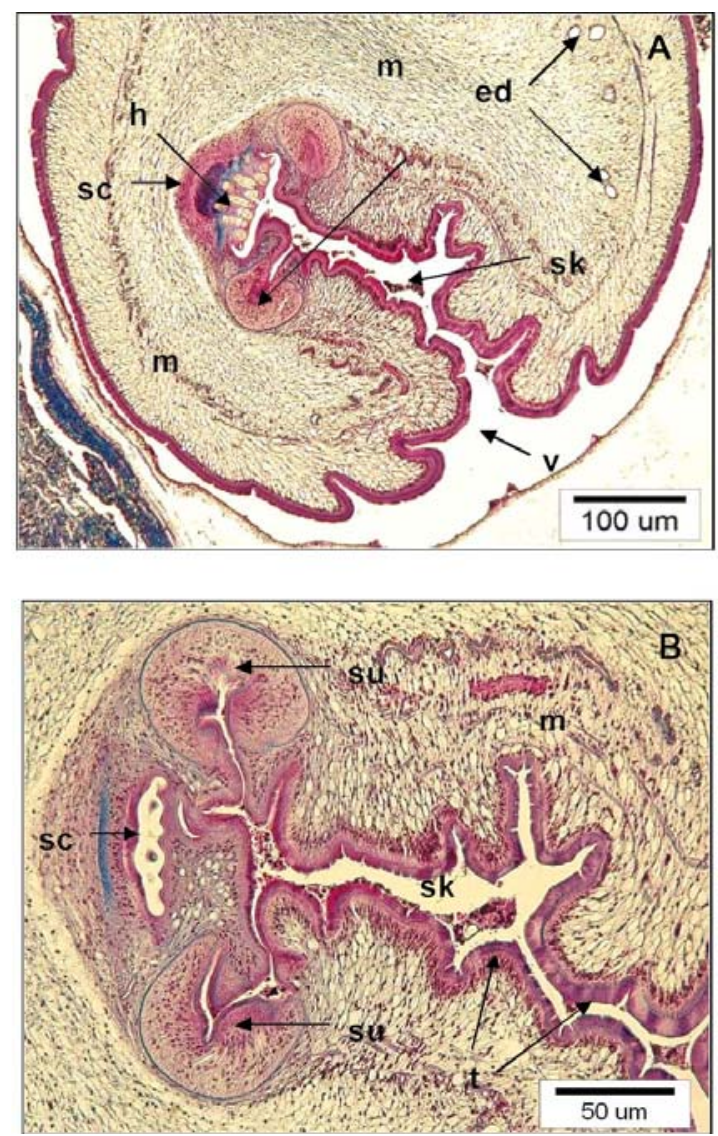

Fig.3. Masson's blue trichrome staining method. Vestibule (v), spiral canal (sk), scolex (sc), suckers (su), hooklets (h), mesenchyme (m), excretory ducts (ed), fibrous capsule (fc) (lungs, A - 100x, B - detail, 400x)

Histological sections were viewed with a light microscope under $\mathrm{x} 100, \mathrm{x} 200$ and $\mathrm{x} 400$ magnifications in conjunction with Olympus SP350 and Olympus BX50 camera. Images were then analyzed using DP-Soft version 3.1 software.

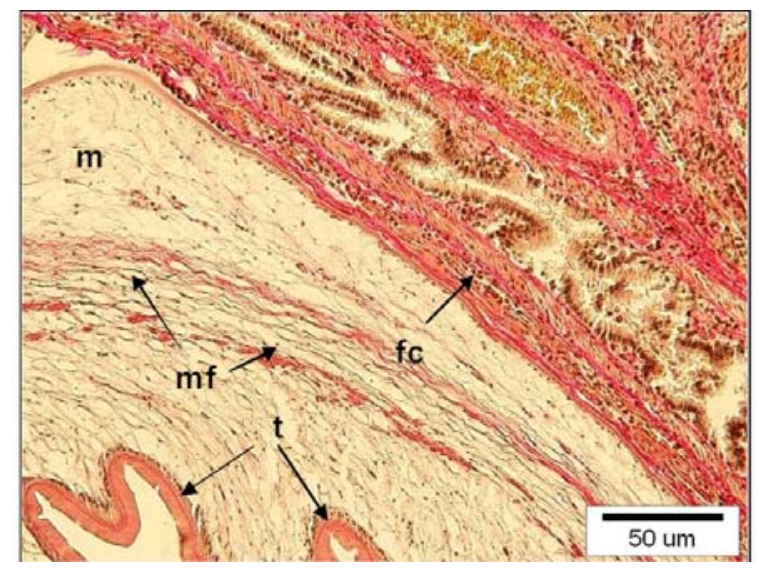

Fig.4. Van Gieson's Pikrofuchsin staining method. Fibrous capsule (fc), tegument (t), mesenchyme (m), muscle fibres (mf) (lungs, 200x)

\section{Results}

In the series of histological sections stained with H\&E, mature viable vesicles of Cysticercus spp. with completely developed invaginated scolex were found. The cysticerci were spherical or oval in shape, approximately pea size $(5$ x $8 \mathrm{~mm}$ ), whitish, and were filled with a watery transparent fluid.

In our histological sections, cysticerci with typical morphological signs of viable cysticerci, scolex and neck were recorded. The scolex was solid, bearing four suckers and rostellum with two rows of hooks, filled with mesenchyme, which is typical for Cysticercus spp. The scolex itself, and the neck area, were covered by tegument, forming numerous primary and secondary folds. Thick layer of tegument without microvilli, the characteristic feature of the neck area, was also observed. Moreover, all above histological findings were achieved in each staining method in all collected viable cysticerci from red or roe deer.
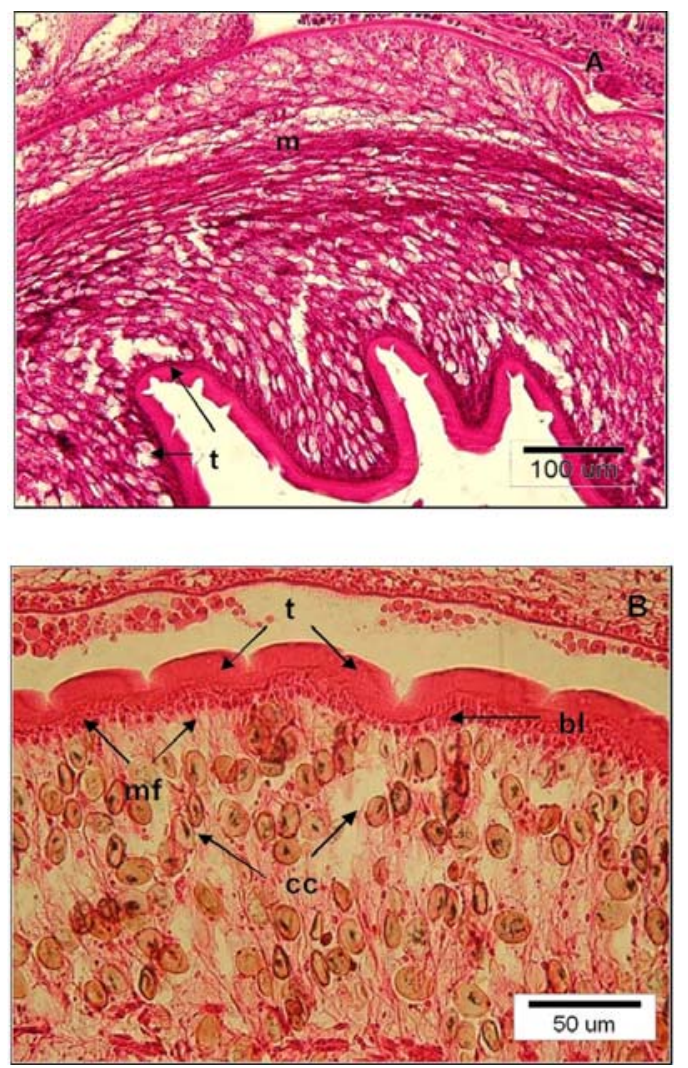

Fig.5. Various histochemical staining methods. Tegument $(\mathrm{t})$ mesenchyme (m), calcareous corpuscules (cc), basal layer (bl), muscle fibres (mf) (A - PAS-method, lungs, 200x, B - Van Kossa method \& nuclear red, heart, 400x)

Cysticerci were distinctly marked by a fibrous capsule from the surrounding tissues. Sometimes the section comprised a fibrous wall, a fully distended bladder membrane, or more often collapsed against the scolex. Leukocytes consisting mostly of lymphocytes, plasma cells, eosinophils and sporadic isolated macrophages infiltrated the tissues. Histologically, a slight inflammatory reaction was 
observed in the surrounding tissues. The intermediate host tissue formed by the fibrous capsule was composed exclusively of parallely arranged collagen fibres with sporadic infiltration of leukocytes. The superficial part of the bladder did not enter into the spiral canal, but it extended and formed the spiral vestibule. The vestibule was separated by the parenchymal part and the spiral canal ended with a tightly invaginated scolex leading into the vestibule. (Fig $1,3)$.

The special histological staining methods serve especially for distinguishing the components of connective tissue (GGT, MBT \& VGP). They are important for differentiating dense regular connective tissues (collagen fibres - the host fibrous capsule) from elastic fibres (total absence in the parasite body) and muscular tissue (muscle fibres and suckers). These staining techniques are very effective for photo documentation as well. (Fig. 2, 3, 4, 5).

The bladder wall of cysticercus consists of several different layers. The outer surface was composed of a thin homogenous eosinophilic and PAS-positive layer tegument (neodermis). Numerous microvilli were projected from this dense layer (Fig. 2B). Under the tegument, a thin fibrous basal layer as well as the muscles and thin connective tissue - mesenchyme with the excretory ducts were observed. Under the basal layer, and the layer of dense parallely arranged spindle shaped muscle fibres, that passes continuously into the thin connective tissue, a mesenchyme was localized.

The mesenchyme is extremely rich in various carbohydrates (e.g. glycogen) and has PAS-positive reaction (Fig. $5 \mathrm{~A})$. In the mesenchyme loosely arranged tubular structures, the excretory ducts and numerous dark staining nuclei, without apparent cytoplasm of mesenchymal cell were observed. The rest of the body was filled by the mesenchyme that contained numerous specific calcareous corpuscles (calcospherules). The calcareous corpuscles are round or oval, usually composed of concentric layers of calcium, and thus stain positively with VK histochemistry method (Fig 5B).

Although it is not possible to differentiate cysticerci on morphological grounds obtained with histological methods, according several biological characteristics we suggest that the cysticerci may belong to Taenia krabbei (heart muscles) and T. hydatigena (lungs).

\section{Discussion}

Here we present a histopathological study of viable cysticerci from deer with a detailed description of their structure. Precise knowledge of specific structures of the viable cysticerci allowed diagnosis of dead cysticerci in histopathological detection (Šlais, 1973). Identification of dead cysticerci is based on comparing similar histological characteristics, with knowledge that all stages of degeneration, disintegration, and calcification may occur. A marked inflammatory reaction around the parasite and the host tissue could be found. Polymorphonuclear cells predominate in recently prepared specimens, while granulocytes, lymphocytes, and macrophages predominate in those dead for longer periods. Granulation tissue and fibrosis are observed in tissue, and Charcot-Leyden crystals may be present in biopsy and necropsy (Gutierrez, 1990).

In the histopathological study, Chacko et al. (2000) found that these calcified intracorporeal vacuoles are more resistant against degenerative and reparative processes in the tissue. The function of the calcareous corpuscles is unknown; however they dissolve easily in acid fixatives or acid hematoxylin. They are one of the most important histological markers of cestode tissue (larva or adult). The calcareous corpuscles are round or oval, usually composed of concentric layers of calcium, and thus stain positively with the VK histochemistry method. The persistence of calcareous corpuscles and/or hooklets may be the only recognizable structures in dead cysticerci. These ovoid bodies may occasionally be the sole parasitic remains seen in a biopsy; therefore their finding is pathognomic for larval stages of tapeworms. In our study, we detected calcareous corpuscles with a selective histochemical technique, a Van Kossa (VK), which confirmed presence of calcium.

Other reports show that calcareous corpuscles are also formed in the excretory canals of cysticerci, indicating their possible contribution in the regulation of osmolarity (Mackiewicz \& Ehrenpris, 1980) and the focal condensation of excessive calcium that protects the parasite from abnormal calcification (Vargas-Parada \& Laclette, 1999). The number, size, shape, and the chemical composition of calcareous corpuscles vary between different cestode species, as well as within the same species (Brand et al., 1969) and appear to be related to the composition of the microenvironment (Baldwin et al., 1978).

Our histopathological findings were similar to descriptions of early stages of cysticercosis (Chi \& Chi, 1978). Massive proliferation of epithelioid cells was absent in our findings. This was probably caused by the host tissue reactions (e.g. topographic localisation, immunological status and stages of parasitic development). A slight infiltration of leukocytes in the host tissue was also recorded (Kolár et al., 1978).

Immunohistochemical and molecular methods for the diagnosis of larval stages of cestodes are more useful in human medicine for diagnosis of neurocysticercosis (Del Brutto et al., 2001) and in veterinary medicine to diagnose bovine cysticercosis especially for Cysticercus bovis (Ogunremi et al., 2004). Till to date for the diagnosis of cysticecosis in cervids no antigen specific antibodies are prepared because of high antigen variability in cestodes. Amongst histological staining methods used in the study, the H\&E method is the most suitable histological method for differentiation of the basic basophilic and eosinophilic structures and for assessment of the presence of cellular infiltration. Histochemical methods are effective for confirmation and demonstration of PAS-positive substances in the body of parasitic tissue (tegument and mesenchyme basic amorphous extracellular matrix) using the McManus - PAS method. The histochemical method according to 
Van Kossa is very effective for distribution of calcium (calcareous corpuscles) and detection of calcification in host tissue in the late period of cysticercosis. The histopathological detection of cysticerci from biopsy is considered the most appropriate direct method for confirmation and diagnostics of the human and animal cysticercosis. This fact remains despite the presence of modern medical immunological (Enzyme-Linked Immunosorbent Assay ELISA and EITB - Electro-Immuno Transfer Blot assay) and biophysical methods (Computer Tomography - CT and Magnetic Resoncance Imaging - MRI). Histopathological methods are still the primary diagnostic methods used.

\section{Acknowledgements}

We gratefully acknowledge material and technical assistance and support A. Hantkeová, L. Háberová, A. Horňáková \& H. Mattová. This study was supported by a grant VEGA SR No. 1/4385/07

\section{References}

BAldwin, J. L., Berntzen, A. K., Brown, B. W. (1978): Mesocestoides cortication concentration in calcareous corpuscles of tetrathyridia grown in vitro. Exp. Parasitol., 44: $190-196$

Brand, T., Nylen, M. U., Martin, G. N., Churchwell, F. K., Stites, E. (1969): Cestode calcareous corpuscles: phosphate relationships, crystallization patterns and variations in size and shape. Exp. Parasitol., 25: 291 - 310

ČunderlíkovÁ, M., BALÁžOVÁ, V. (1990): Selected chapters from histological techniques. Osveta Martin, Slovakia, 167 pp. [In Slovak]

Del Brutto, O. H., Rajshekhar, V., White, A. C., Tsang, V. C. JR., Nash, T. E., Takayanagui, O. M., Schantz, M. P., Evans, C. A., Flisser, A., Correa, D., Botero, D., Allan, J. C., Sarti, E., Gonzalez, A. E. Gilman, R. H., GARCIA, H. H. (2001): Proposed diagnostic criteria for neurocysticercosis. Neurology, 57: $177-183$

FlueCK, W. T., JONES, A. (2006): Potential existence of a sylvatic cycle of Taenia ovis krabbei in Patagonia, Argentina, Vet. Parasitol., 135: 381 - 383

GuTIERREZ, Y. (1990): Diagnostic pathology of parasitic infections with clinical correlations. Lea \& Febiger, Philadelphia, London, 432-447

ChackO, G., RAJSheKhar, V., Chandy, M. J., ChAndi, S. M. (2000): The calcified intracorporeal vacuole: an aid to the pathological diagnosis of solitary cerebral cysticercus granulomas. J. Neurol. Neurosurg. Psychiatr., 69: 525 - 527 CHI, H. S., CHI, J. G. (1978): A histopathological study on human cysticercosis. Korean J. Parasitol., 16: 123 - 133 Christiansen, M. (1931): Die muskelfinne des rehes und deren bandwurm (Cysticercus et Taenia cervi n. sp. ad interim). Z. Parasitenkd., 4: 75 - 100 [In German]

KOLÁR̆, Z., ZAJÍČEK, D., LÁVIČKA, M. (1978): Developmental stages of Taenia krabbei Moniez, 1879 (Cysticercus tarandi) in deer (Capreolus capreolus L.) in Czechoslovakia. Vet. Med. (Praha), 23: $251-256$

Kotrlý, A., Kotrlá, B. (1977): Helminths of wild ruminants introduced into Czechoslovakia. Folia Parasitol., 24, $35-40$

MACKIEwICZ, J. S., EHRENPRIS, M. B. (1980): Calcareous corpuscles distribution in caryophyllid cestodes: possible evidence of cryptic segmentation. Proc. Helminthol. Soc. Wash., 47: $1-7$

MituCH, J. (1969): Helmintofauna of wild ungulates. Českoslov. ochrana prírody - Czech, 8: 237 - 250

MurAi, E., SugÁR, L. (1979): Taeniid species in Hungary (Cestoda, Taeniidae). I. Cysticercosis, coenurosis and hydatidosis of wild ungulates. Parasitol. Hung., 12: 41 - 52

Ogunremi, O., Macdonald, G., Geerts, S., Brandt, J. (2004): Diagnosis of Taenia saginata cysticercosis by immunohistochemical test on formalin-fixed and paraffin-embedded bovine lesions. J. Vet. Diagn. Invest., 16: 438 - 441 ROMANENKO, L. N. (1988): Ultrastructure of the tegumentum surface of Cysticercus ovis and C. tarrandi from various intermediate hosts. Tr. Vsesoyuznogo Inst. Gel'mintol. im. Skryabina, 29: 111 - 115

Rukavina, J., CANKOvic, M., KubelKa, D. (1973): Cysticercosis (cervi) in roe deer. Veterinaria Sarajevo, 22: 409 $-412$

ŠLAIS, J. (1973): Functional morphology of cestode larvae. Adv. Parasitol., 11: $395-480$

Tropilo, J., KatKiewicz, M. T., Wisniewski, J. (2001): Sarcocystis spp. infection in free-living animals - wild boar (Sus scrofa L.), red deer (Cervus elaphus L.), roe deer (Capreolus capreolus L.). Pol. J. Vet. Sci., 4: 15 - 18

VACEK, Z. (1995): Histology and histological technique. Institute for further education of medical staff. Brno, pp. 184 [In Czech]

VARGAS-PARADA, L., LACLETTE, J. P. (1999): Role of the calcareous corpuscles in cestode physiology: a review. Rev. Latinoam. Microbiol., 41: 303 - 307

VERSTER, A. (1969): A taxonomic revision of the genus Taenia Linnaeus, 1758. Onderstepoort J. Vet. Res., 36: 3 - 58 